\title{
Thermodynamic analysis and optimization of an irreversible nano scale dual cycle operating with Maxwell-Boltzmann gas
}

\author{
Mohammad H. Ahmadi ${ }^{1, a}$, Mohammad Ali Ahmadi², Fathollah Pourfayaz ${ }^{1}$, \\ Michel FeidT ${ }^{3}$ AND EMin ACIKKALP ${ }^{4}$ \\ 1 Department of Renewable Energies, Faculty of New Sciences and Technologies, University of Tehran, Tehran, Iran \\ 2 Department of Petroleum Engineering, Ahwaz Faculty of Petroleum Engineering, Petroleum University of Technology (PUT), \\ Ahwaz, Iran \\ 3 Laboratoire d'Energétique et de Mécanique Théorique et Appliquée, ENSEM, 2 avenue de la Forêt de Haye, \\ 54518 Vandoeuvre-lès-Nancy, France \\ ${ }^{4}$ Department of Mechanical and Manufacturing Engineering, Engineering Faculty, Bilecik S.E. University, Bilecik, Turkey
}

Received 14 October 2015, Accepted 14 March 2016

\begin{abstract}
In last decades, nano technology was developed. Since, nano scale thermal cycles will be possibly employed in near future. In this research, a nano scale irreversible dual cycle is investigated thermodynamically for optimization of performance. Ideal Maxwell-Boltzmann gas is used for working fluid in the system. It is chosen as working fluid. In this paper, two scenarios are introduced for optimization process. The outcomes of each of the scenarios are evaluated independently. Throughout first scenario, in order to maximize the dimensionless output work and first law efficiency of the system, multi-objective optimization algorithms are employed. Furthermore, in second scenario, two objective functions comprising the dimensionless output work are the dimensionless ecological function are maximized concurrently via employing multi objective optimization algorithms. The multi objective evolutionary approaches (MOEAs) on the basis of NSGA-II method are employed in this paper Decision making is done via three methods including LINAMP and TOPSIS and FUZZY. Finally, error analysis is implemented on the results obtained in this research
\end{abstract}

Key words: Dual cycle / dimensionless ecological function / dimensionless output work / optimization / decision making

\section{Introduction}

Performance optimization of machines and heat engines was always a challenging topic for all engineers and experts working in the area of thermo fluid science. Sadi Carnot was the first researcher who introduced the most efficient thermal engine which was totally reversible (externally and internally). The maximum possible thermal efficiency within two temperatures is given in this engine with no other engine more efficient than that. Finitetime thermodynamics (FTT) was introduced then as a solution for better performance analysis of thermodynamic cycles. Curzon-Ahlborn-Novikov (CAN) $[1,2]$ engine first introduced the FTT based engine. This engine is internally reversible (endoreversible), and externally irreversible. After that, new methods for performance evaluations were presented. Angulo-Brown [3] presented the

\footnotetext{
a Corresponding author:

mohammadhosein.ahmadi@gmail.com
}

ecological function (ECF) and Yan [4] improved it. This criterion is described as

$$
E C F=W-T_{0} S_{\text {gen }},
$$

where $W$ is defined as the output work, $T_{0}$ as environment temperature and $S_{\text {gen }}$ as entropy generation. There are a number of ecological function based papers in the open literature [5-36] which consider the ecological functions for optimization procedure. For example $E P C=\frac{E x}{T_{0} S_{\text {gen }}}$ where $E x$ is output exergy of the system or

$$
E C O P=\frac{W}{T_{0} S_{\text {gen }}}
$$

where $W$ is the output power and $S_{\text {gen }}$ is entropy generation. Chen et al. [5] performed an optimization for generalized irreversible universal heat-engine cycles based on power, efficiency, entropy generation rate and ecological function. Also, with finite time thermodynamics, the 


\section{Nomenclature}

\begin{tabular}{|ll|}
\hline$c_{p}$ & Specific heat at constant pressure \\
$c_{v}$ & Specific heat at constant volume \\
$E C O P$ & Ecological coefficient of performance \\
$E x$ & Output exergy \\
$E C F$ & Ecological function \\
$E P C$ & Exergetic performance criterion \\
$e c f$ & Dimensionless ecological function \\
$L_{c}$ & Half of the most probable \\
& Broglie's wave length \\
$H$ & Stroke length \\
$k$ & Boltzmann constant \\
$h$ & Planck constant \\
$m$ & Mass \\
$M A W$ & Maximum available work \\
$m a w$ & Dimensionless maximum available work \\
$N$ & Number of particles \\
$R$ & Diameter \\
$Q$ & Heat \\
$S$ & Entropy generation rate \\
$T$ & Temperature (K) \\
$V$ & Volume \\
$W$ & Output work \\
$x$ & Compression ratio \\
$y$ & Pressure ratio \\
$z$ & Cut-off ratio \\
\hline & \\
\hline$\eta$ & First law efficiency \\
\hline & \\
\hline
\end{tabular}

performance analysis of the system consisting two cooling branches, two heating branches and two adiabatic branches with losses of heat resistance, heat leak and internal irreversibility were done to present an improvement in the analysis of real heat engines. Chen et al. [6] considered a generalized irreversible heat engine with losses due to heat resistance, leakage and internal irreversibility and optimized the engine using an ecological objective function which takes into account the power and entropy production rate of the heat engine. Also, the effects of heat leakage and irreversibility were examined. Huang et al. [7] optimized an irreversible four-temperature-level absorption heat pump with considering losses of heat resistance and internal irreversibility. An ecological function consisting heating load, coefficient of performance and entropy production rate were considered for optimization. The optimization procedure led to a decrease in entropy production rate in cycle and an appropriate decrease in heating load. Yan et al. [8] proposed an irreversible three-heat-source refrigerator and optimized the cycle with a compromise between cooling rate and entropy production rate. An ecological criterion was written as $E=R-\lambda T_{0} \sigma$ where $R$ is the cooling rate of the refrigerator and $\sigma$ is the rate of entropy generation and $\lambda$ is the dissipation coefficient of the cooling rate which were proved to be equal with coefficient of performance. Chen et al. [12] presented an exergy-based ecological function for a generalized irreversible Carnot-engine with heat resistance, heat leakage and internal irreversibility and optimized the engine based on a compromise between the output power and entropy-production rate of engine and an assumption of linear phenomenological heat transfer law. Zhu et al. [13] performed an optimization of ecological objective function for a generalized irreversible Carnot engine with considering losses of heat resistance, heat leakage and internal irreversibility. In this study, generalized heat transfer laws were assumed to be as $Q=(\delta T)^{n}$. Same authors [14] performed an exergy based optimization with ecological objective function as $E=P-T_{0} \sigma$ which consists output exergy rate and exergy-loss rate of a heat pump. Ecological coefficient of performance (ECOP) and exergetic performance coefficient are other criteria that were submitted by Ust et al. [37-51]. Ust et al. [37] presented a new thermo-ecological criterion based on coefficient of performance (ECOP) which is defined as the ratio of output power to the loss rate of availability. Results showed that optimized ECOP has advantage in terms of entropy-generation rate and thermal efficiency and fewer disadvantages on output work compared to objective functions in the literature. The same authors [38] applied their new thermo-ecological criterion on an irreversible refrigerator for optimization of performance. It was defined as the ratio of the cooling load to the loss rate of availability (entropy generation) as $E C O P=\frac{\dot{Q}_{L}}{T_{0} \dot{\sigma}}$. Design parameters that maximize the objective function were investigated. They [39] also considered an irreversible regenerative-Brayton heat engine and optimized the cycle using ecological function defined as $\dot{E}=\dot{W}-T_{0} \dot{S}_{g}$ and $E C O P=\frac{W}{T_{0} S_{\text {gen }}}$. The results show that the optimization criterion is advantageous in terms of higher thermal efficiency and lower entropy-generation rate and lower investment cost but is disadvantageous in terms of output power compared to $\dot{E}_{\max }$ and $W_{\max }$. Sogut et al. [40] performed an analysis on irreversible closed Brayton heat engines with variable temperature of heat reservoirs. The effects of intercooling and regeneration were investigated on the mentioned engine with considering $E C O P, \dot{E}_{\max }$ and $\dot{W}_{\max }$. Results show that the optical total isentropic temperature ratio and intercooling isentropic temperature ratio at $E C O P_{\max }$ are less compared to $E_{\max }$ and $\dot{W}_{\max }$ which contributes to cost savings. Ust et al. [41] investigated the effect of regeneration on irreversible air refrigerators having finite-rate heat transfer, heat leakage and internal irreversibilities based on thermo-ecological criteria including ECOP, $\eta_{e x}$ and COP. Results show that optimal thermodynamic condition is the same for all criteria but ECOP gives information on entropy generation too including loss rate of availability. Same authors [42] optimized the air refrigeration cycles based on ecological coefficient of performance (ECOP). Akkaya et al. presented an exergetic evaluation for SOFC/GT CHP systems. They also, with an EPC criterion defined as $E P C=\frac{\dot{E}_{\text {out }}}{E x_{D, \text { tot }}}$ optimized the system for minimum entropy-generation rate. The results show that the least entropy-generation rate for a given 
output exergy was obtained in the SOFC/GT [48]. The cycle includes irreversibilities of finite-rate heat transfer, heat leakage and internal dissipations. The results show that the optimal conditions for ECOP and COP were the same. However, COP gives information about power needed for cooling load and ECOP gives information on entropy generation rate including loss rate of availability which is a great tool for evaluating the system. Açıkkalp and Yamık [52] presented criterion called maximum available work which is defined as $M A W=$ $Q_{H}\left(1-\frac{T_{0}}{T_{H}}\right)-T_{0} S_{\text {gen }}$. Besides, nanotechnology has gained great attention during last decade and in the recent years this is entered through thermodynamic cycles. As a result, it can be said that nano-scale thermal cycles may be of great importance in near future. Because of this, quantum thermodynamics will gain attention in near future. In the open literature, there are studies about nano-scale thermodynamics or thermal cycles which use quantum gases [53-75]. Lucia [76-80] presented papers on entropy generation and quantum mechanics. Some papers are submitted about dual cycles, but there is few paper on dual cycles working with Maxwell-Boltzmann gas [80-83].

Optimization of a problem with multi-objectives has a significant importance in engineering area [84-86]. Various methods including evolutionary algorithms (EA) were introduced in 20th century for unraveling multi-variable and multi-objective issues $[87,88]$. The outcomes achieved from multi-objective optimization are groups of answers named Pareto frontier which reveals reasonable answers. Various scholars employed this method in engineering area specially in energy engineering applications [89-107].

In this work, two optimization scenarios are defined for the nano scale irreversible dual cycle. In first scenario, in order to maximize the dimensionless output work and First law efficiency of the system, MOEA was used. Moreover, two objective functions including the dimensionless output work and the dimensionless ecological function were considered in the second scenario in order to maximizing at the same time via MOEA. Three decision makers comprising LINMAP, TOPSIS and Fuzzy approaches were employed as decision makers. Finally, analysis of deviation (error) was performed on the outcomes achieved from each decision maker.

\section{Thermodynamic analysis}

In this part, the thermodynamic analysis of a nano scale dual cycle is carried out. In the thermodynamic analysis, a nano scale cylinder is presumed. Its diameter is $R$ and stroke length represents by $H$ as nanometer. Temperature-entropy diagram is depicted through Figure 1. Subscript $s$ denotes ideal conditions. Specific heats at constant volume and constant pressure $\left(\mathrm{J} . \mathrm{K}^{-1}\right)$ for ideal Maxwell-Boltzmann gas can be determined as follows [108]:

$$
c_{v}=\frac{3}{2} N k+N k \frac{L_{c}(T)}{4 \sqrt{\pi}}\left(\frac{1}{R}+\frac{1}{H}\right)
$$

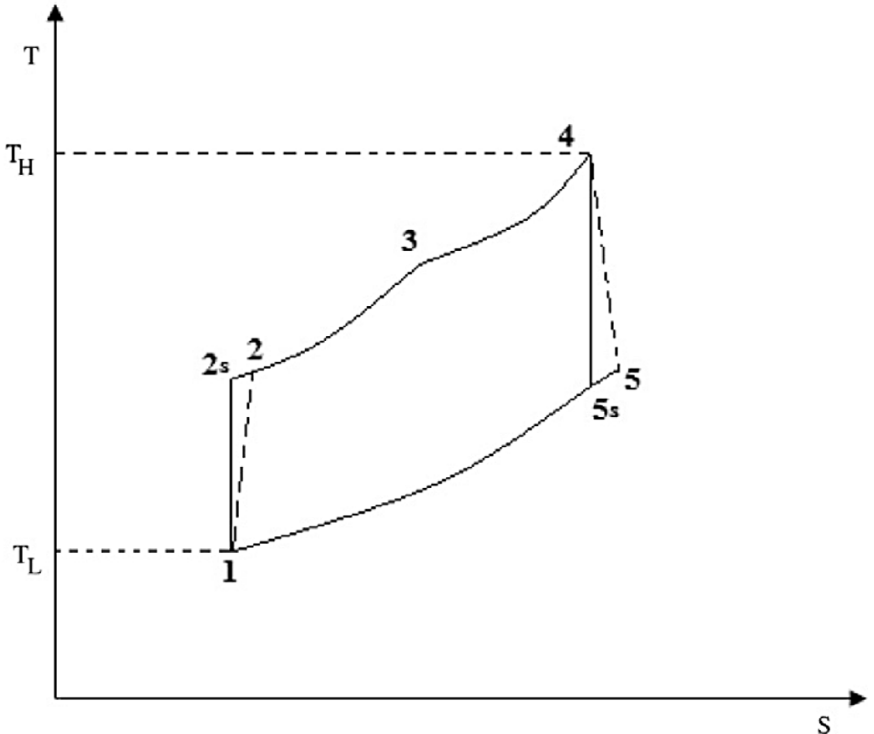

Fig. 1. $T-S$ diagram of irreversible dual cycle.

$$
c_{p}=\frac{5}{2} N k+N k \frac{L_{c}(T)}{4 \sqrt{\pi}}\left(\frac{1}{R}+\frac{1}{H}\right)
$$

In which $N$ stands for the number of particles, $L_{c}$ denotes half of the most probable Broglie's wave length, $h$ represents the Planck constant and $k$ stands for the Boltzmann constant. Heat addition $(\mathrm{J})$ to the system can be calculated as follows:

$$
Q_{H}=\int_{2}^{3} c_{v} d T+\int_{3}^{4} c_{p} d T
$$

and heat rejection $(\mathrm{J})$ from the system:

$$
\begin{aligned}
Q_{L} & =\left(\frac{3}{2} N k T_{5}+N k T_{5} \frac{L_{c}\left(T_{5}\right)}{4 \sqrt{\pi}}\left(\frac{1}{R}+\frac{1}{H}\right)\right) \\
& -\left(\frac{3}{2} N k T_{1}+N k T_{1} \frac{L_{c}\left(T_{1}\right)}{4 \sqrt{\pi}}\left(\frac{1}{R}+\frac{1}{H}\right)\right)
\end{aligned}
$$

Half of the most probable Broglie's wave length at temperature $T$ can be determined as following as [109]:

$$
L_{c}(T)=\frac{h}{\sqrt{8 m k T}}
$$

In which $m$ represents the atomic mass of the gas. Output work of the system $(\mathrm{J})$ is calculated as following as:

$$
W=Q_{H}-Q_{L}
$$

Entropy generation (J.K $\left.\mathrm{K}^{-1}\right)$ of the system can be described:

$$
S_{\text {gen }}=\frac{Q_{L}}{T_{1}}-\frac{Q_{H}}{T_{4}}
$$

and the first law efficiency of the system by:

$$
\eta=\frac{W}{Q_{H}}
$$




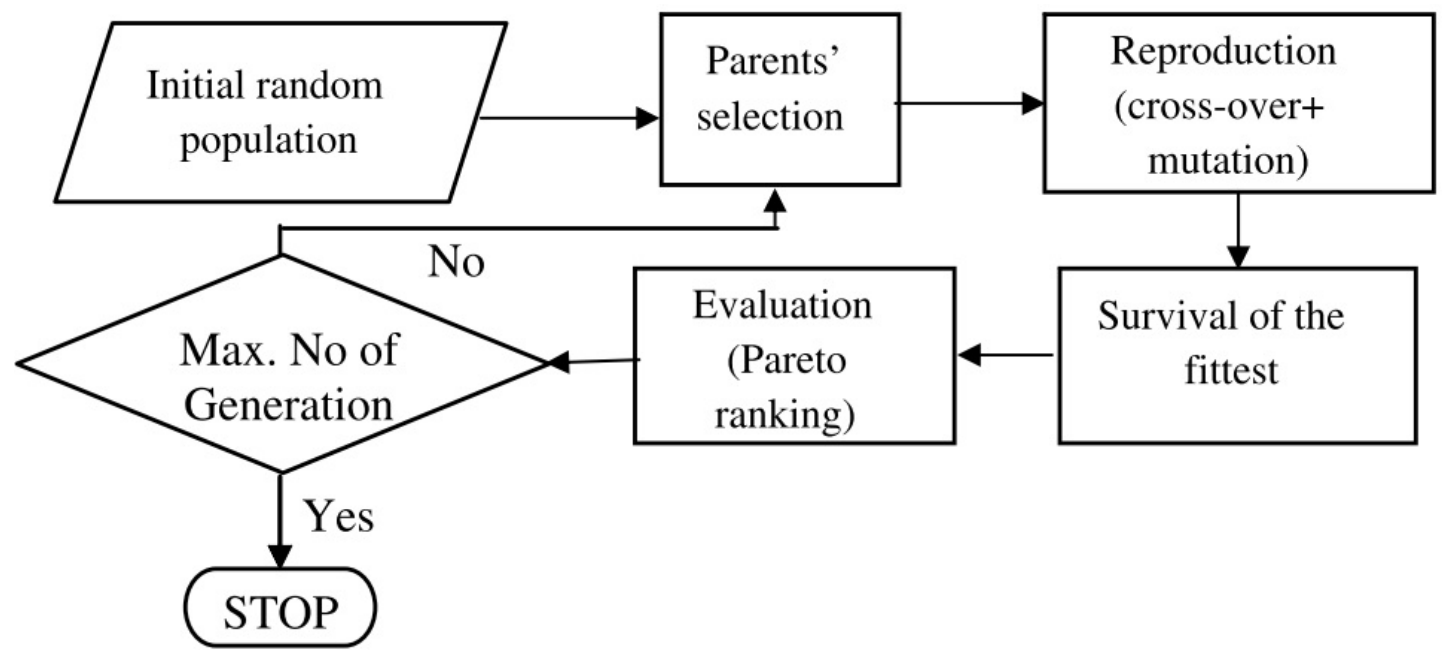

Fig. 2. Scheme for the multi-objective evolutionary algorithm used in the present study [93-101].

Output exergy $(\mathrm{J})$ is described as:

$$
E x=Q_{H}\left(1-\frac{T_{0}}{T_{4}}\right)
$$

In which $T_{0}$ stands for the environment temperature compression ratio $(x)$ and cut-off ratio $(z)$ of the dual cycle $\left(x=\frac{V_{1}}{V_{2}}, z=\frac{V_{3}}{V_{4}}\right)$, ideal temperatures for 2 and 5 points $\left(T_{2 S}=T_{1} x^{0.4}, T_{5 S}=\frac{T_{4} z}{x^{2 / 3}}\right)$. Expansion and compression efficiencies are employed for introducing irreversibilities throughout the cycle.

$$
\begin{aligned}
\eta_{C} & =\frac{T_{2 S}-T_{1}}{T_{2}-T_{1}} \\
\eta_{E} & =\frac{T_{5}-T_{4}}{T_{5 S}-T_{4}}
\end{aligned}
$$

Employing these equations $T_{2}$ and $T_{4}$ are specified as following as:

$$
\begin{aligned}
& T_{2}=\frac{\left(T_{2 S}-T_{1}\right)+\eta_{C} T_{1}}{\eta_{C}} \\
& T_{5}=\eta_{E}\left(T_{5 S}-T_{4}\right)+T_{4}
\end{aligned}
$$

The equation between $T_{2}$ and $T_{3}$ is determined by following equation:

$$
T_{3}=T_{2} y
$$

In which $y$ stands for the pressure ratio $\left(y=\frac{P_{3}}{P_{2}}\right)$. Additional volume equations are described as following as:

$$
\begin{aligned}
& V_{1}=V_{5} \\
& V_{2}=V_{3}
\end{aligned}
$$

ecological function $(\mathrm{J})$ determines via following formula:

$$
E C F=W-T_{0} S_{\text {gen }}
$$

ecological coefficient of performance is calculated as following as:

$$
E C O P=\frac{W}{T_{0} S_{\mathrm{gen}}}
$$

Exergetic performance criterion determines by below equation:

$$
E P C=\frac{E x}{T_{0} S_{\text {gen }}}
$$

Maximum available work $(\mathrm{J})$ calculates as follows:

$$
M A W=E x-T_{0} S_{\text {gen }}
$$

In this paper, dimensionless output work, ECF, $M A W$ and entropy generation are introduced as following as:

$$
\begin{aligned}
w & =\frac{W}{N K T_{4}} \\
e c f & =\frac{E C F}{N K T_{4}} \\
m a w & =\frac{M A W}{N K T_{4}} \\
S_{\text {gen }}^{\prime} & =\frac{S_{\text {gen }}}{N K}
\end{aligned}
$$

\section{Multi-objective optimization}

The MOEA was used to optimize dual cycle system to specify the prior variables of system design. To assess this, Genetic algorithms (GA) implement iterative and stochastic search process to determine optimum solution and track in a simplified behavior theory of biological development. The general concept of Genetic algorithms is depicted through Figure 2. [87,90,99].

\subsection{Objective functions, decision variables and constraints}

The first law efficiency of the system $(\eta)$ and the dimensionless output work $(w)$ are the two objective functions for the first scenario, which are evaluated via Equations (8) and (20). 
The dimensionless output work $(w)$ and the dimensionless ecological function (ecf) are the two objective functions for the second scenario, which are evaluated via Equations (20) and (21).

Three decision variables were assumed as below:

$x$ : the compression ratio

$y$ : the pressure ratio

$z$ : the cut-off ratio

Even though the decision variables would be different in the optimization process, each should be in a proper interval. By assuming the following limits the objective functions are unraveled:

$$
\begin{gathered}
1.9 \leqslant y \leqslant 2.3 \\
1.5 \leqslant z \leqslant 1.7 \\
4 \leqslant x \leqslant 8
\end{gathered}
$$

\subsection{Decision-making during the multi-objective optimization progress}

Decision-making for gathering of the improved best solution from available solutions through the multiobjective optimization method has a central role. There are a number of approaches for decision-making in the decision problems. These approaches could be employed for picking the improved optimum solution from the Pareto frontier. Meanwhile, dimension of the objectives in the multi-objective optimization problem may be diverse. Consequently, unification of the scales and dimensions of the objective space should be performed before making a decision. Vectors of objectives would be nondimensioned prior to the decision-making progress. There are two robust approaches of non-dimensionalization employed in the decision making techniques comprising Euclidean non-dimensionalization, and fuzzy nondimensionalization.

\subsection{Non-dimensionalization methods}

\section{Euclide non-dimensionalization}

$F_{i j}^{n}$ stands for the matrix of objectives for various solutions of the Pareto frontier where $i$ stands for the index of each solution on the Pareto frontier, and $j$ represents the index of the objective in objective region. In this method, a non-dimensioned objective, $F_{i j}^{n}$, is formulated as following as,

$$
F_{i j}^{n}=\frac{F_{i j}}{\sqrt{\sum_{i=1}^{m}\left(F_{i j}\right)^{2}}}
$$

for minimization and maximization goals

\section{Fuzzy non-dimensionalization}

In this method, a non-dimensioned objective, $F_{i j}^{n}$, is calculated as following as,

$$
F_{i j}^{n}=\frac{F_{i j}-\min \left(F_{i j}\right)}{\max \left(F_{i j}\right)-\min \left(F_{i j}\right)} \text { for maximization objectives }
$$

$$
F_{i j}^{n}=\frac{\max \left(F_{i j}\right)-F_{i j}}{\max \left(F_{i j}\right)-\min \left(F_{i j}\right)} \text { for minimization objectives }
$$

In this research the most well-known and standard types of decision-makers including LINMAP, TOPSIS and fuzzy Bellman-Zadeh methods were employed to achieve the optimum answer. It is worth to mention that all the required information regarding these decision makers can be found in references [89,90,100-102]. The BellmanZadeh method employs the fuzzy non-dimensionalization; however, the two rest methods employ Euclidean nondimensionalization.

\section{Results and discussion}

The sensitivity of the objective functions to the decision variables was examined. As illustrated in Figure 3a, the first law efficiency of the system decreased considerably with increasing the pressure ratio $(y)$ at various values of the compression ratio $(x)$. As illustrated in Figure $3 \mathrm{~b}$, the dimensionless output work decreased considerably with increasing the pressure ratio $(y)$ at various values of the compression ratio $(x)$. As has been shown, in a fixed amount the pressure ratio $(y)$ maximum amount of dimensionless work is related to $x=6$. This indicates that for compression ratio $(x)$ an optimal value is between $x=6$ and $x=8$. By increasing the value of $y$, the value of $Q_{H}$ decreased. $w$ value for the system decreased with decreasing $Q_{H}$. As illustrated in Figure 3c, the dimensionless ecological function (ecf) decreased considerably with increasing the pressure ratio $(y)$ at various values of the compression ratio $(x)$. By increasing the value of $y$, the value of $Q_{H}$ decreased. $W$ value for the system decreased with decreasing $Q_{H}$. Also, $S_{\text {gen }}$ values for the system increased with decreasing $Q_{H}$.

As depicted in Figure 4a, the first law efficiency of the system decreased significantly with increasing the cut-off ratio $(z)$ at various values of the compression ratio $(x)$.

As illustrated in Figure 4b, the dimensionless output work decreased considerably with increasing the cut-off ratio $(z)$ at various values of the compression ratio $(x)$. As has been shown, in a fixed amount the cut-off ratio $(z)$ maximum amount of dimensionless work is related to between $x=6$ and $x=8$. This indicates that for compression ratio $(x)$ an optimal value is between $x=6$ and $x=8$. As illustrated in Figure $4 \mathrm{c}$, the dimensionless ecological function (ecf) decreased considerably with increasing the cut-off ratio $(z)$ at various values of the compression ratio $(x)$. 
M.H. Ahmadi et al.: Mechanics \& Industry 18, 212 (2017)

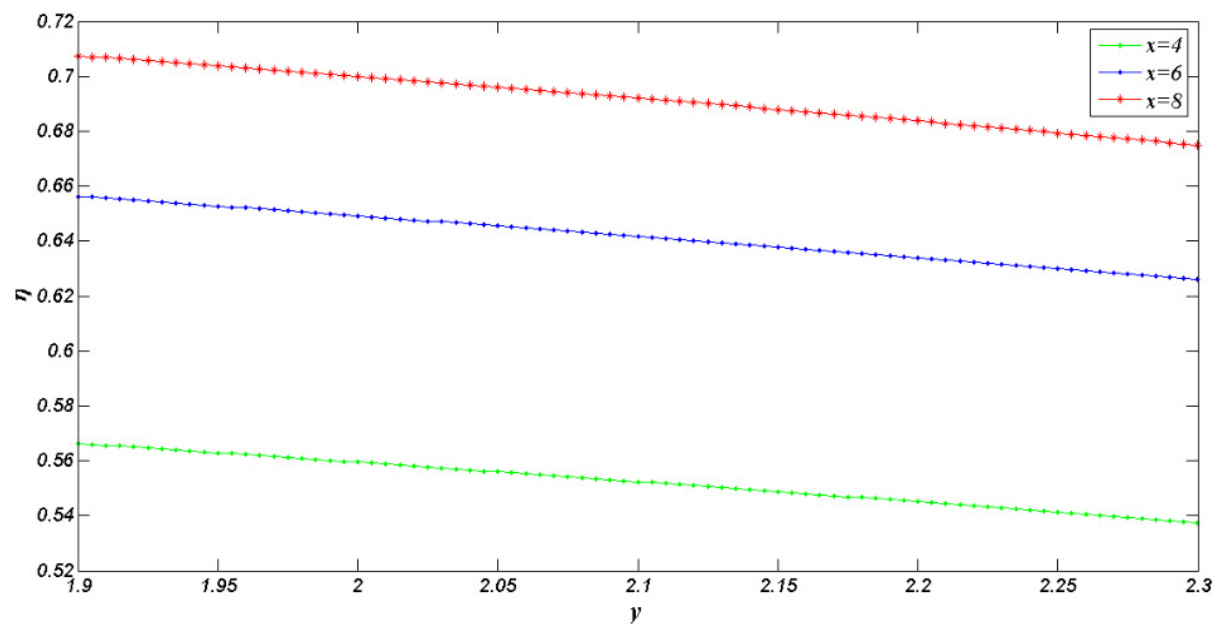

(a)

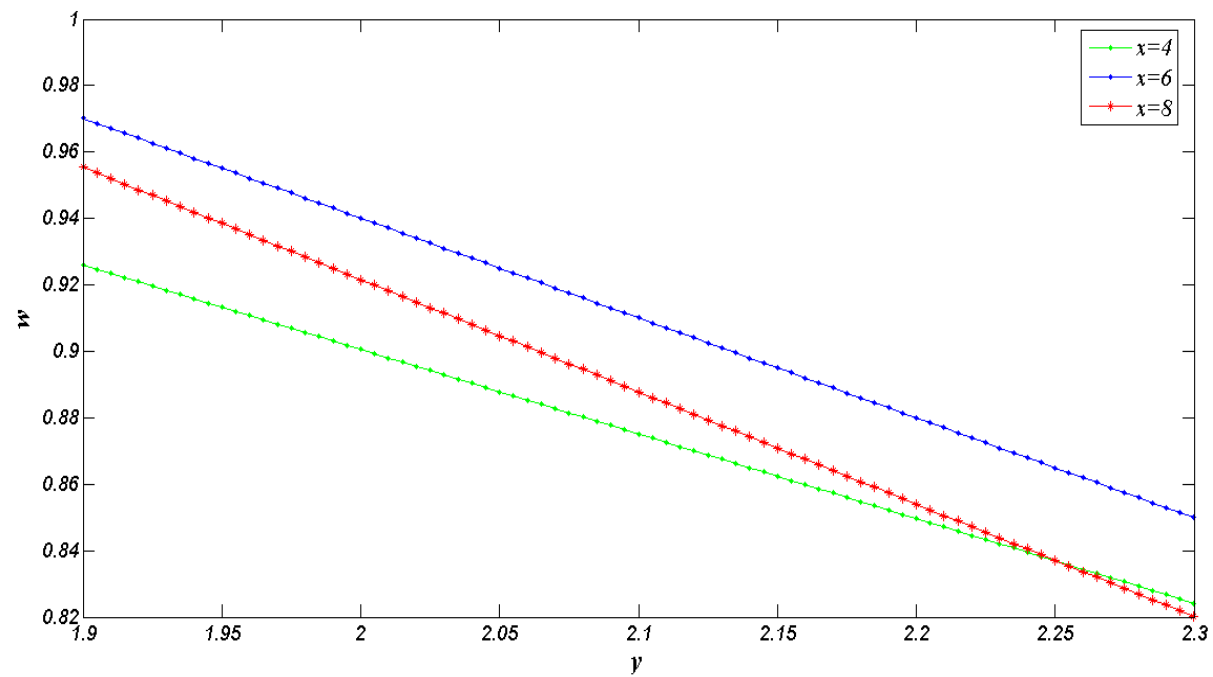

(b)

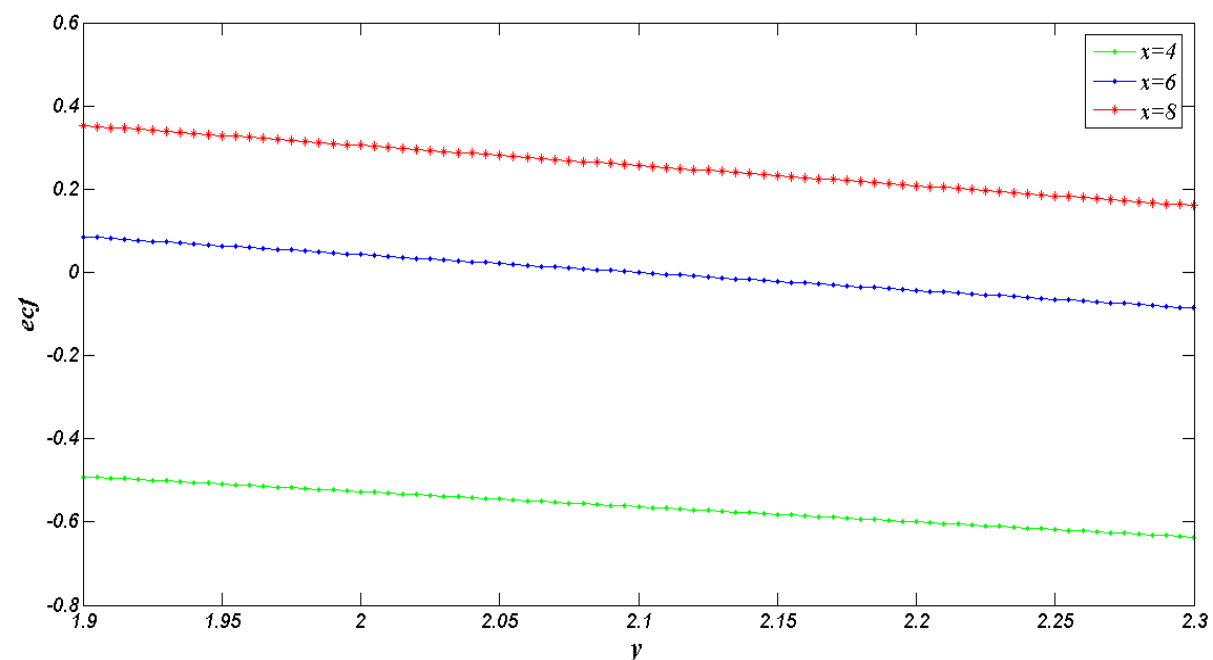

(c)

Fig. 3. Effects of the pressure ratio $(y)$ and the compression ratio $(x)$ on the (a) first law efficiency, (b) dimensionless output work, (c) dimensionless ecological function. 
M.H. Ahmadi et al.: Mechanics \& Industry 18, 212 (2017)

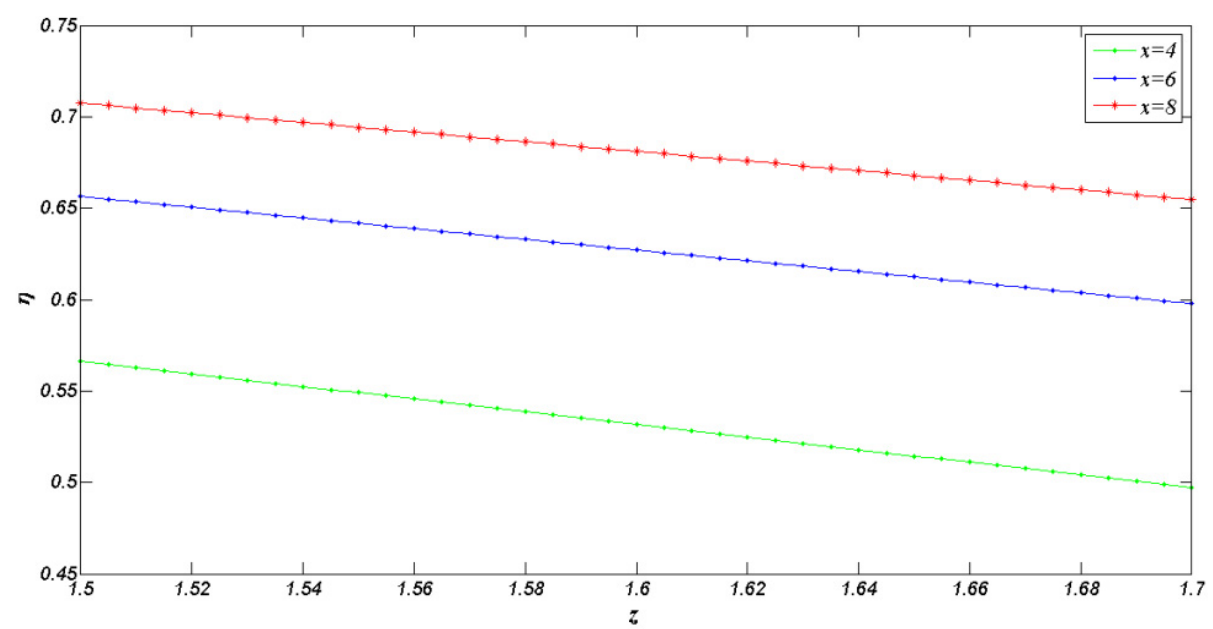

(a)

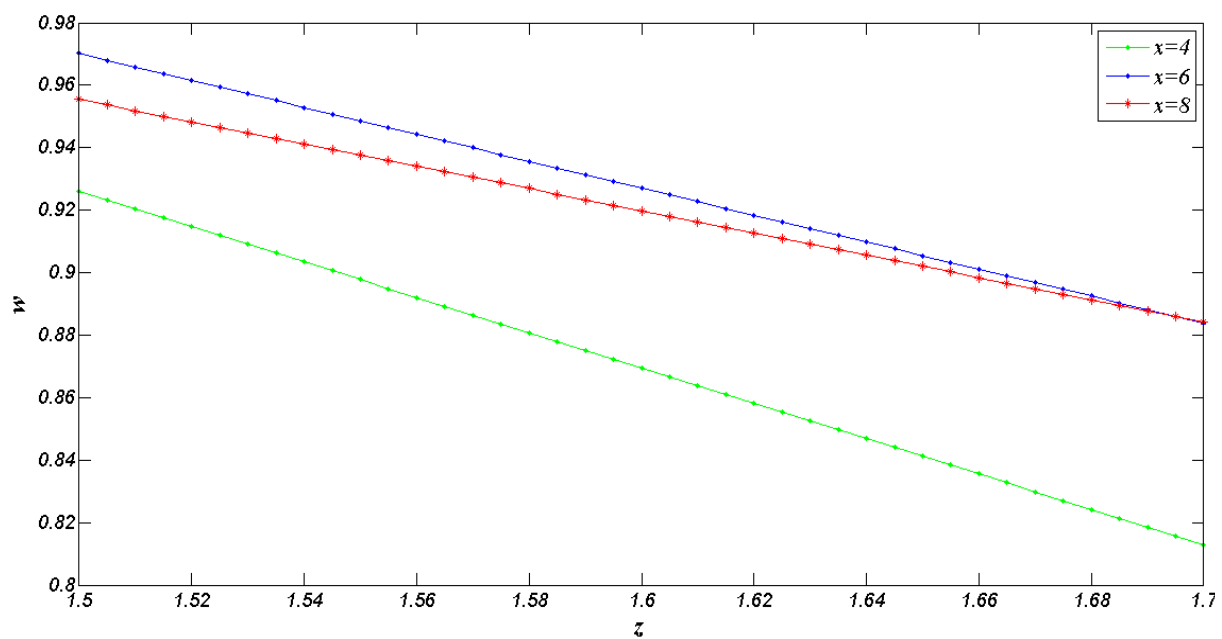

(b)

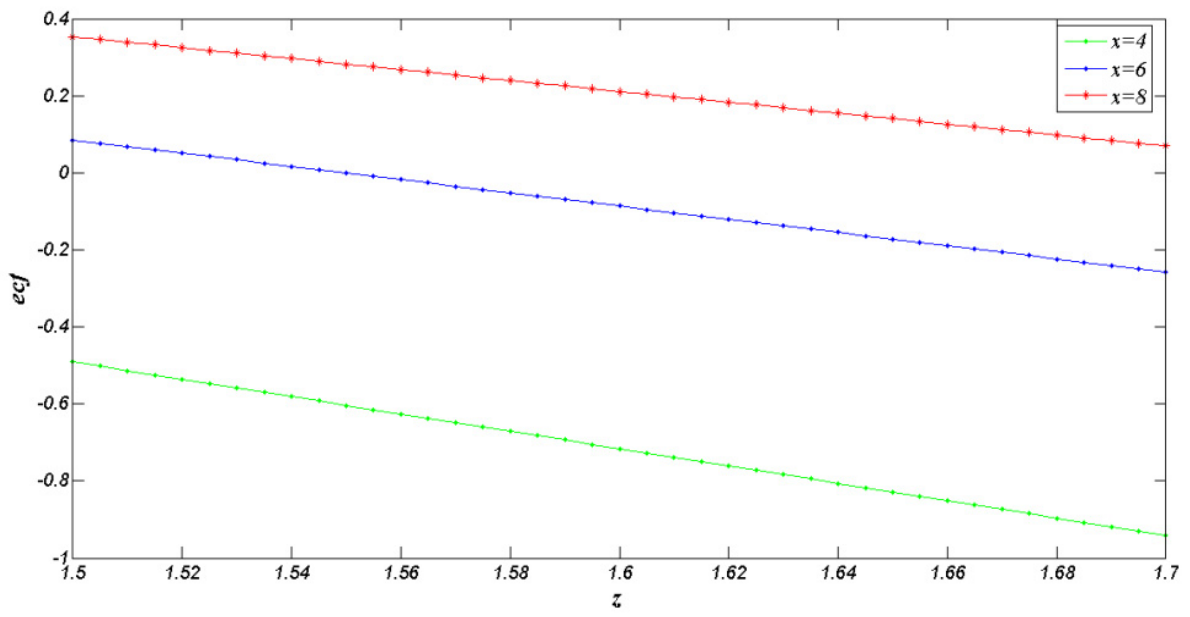

(c)

Fig. 4. Effects of the cut-off ratio $(z)$ and the compression ratio $(x)$ on the (a) first law efficiency, (b) dimensionless output work, (c) dimensionless ecological function. 


\subsection{Results of first scenario}

Using MOEA based on the NSGA-II algorithm, the first law efficiency of the system $(\eta)$ and the dimensionless output work $(w)$ are maximized simultaneously. The objective functions and the boundaries which were employed in the optimization process are formulated by Equations (8) and (20) and Equations (24) and (26) respectively. The compression ratio, the pressure ratio and the cut-off ratio are assumed as design variables. Following properties of the nano scale irreversible dual cycle system are presumed as below [110]:

$$
\begin{aligned}
R & =10^{-8}(\mathrm{~m}), H=3 \times 10^{-8}(\mathrm{~m}), T_{4}=700(\mathrm{~K}), \\
T_{1} & =100(\mathrm{~K}), k=1.0381 \times 10^{-23}(\mathrm{~J}), \\
h & =6.6262 \times 10^{-34}(\mathrm{~J} . \mathrm{s}), \\
m & =6.6474 \times 10^{-27}(\mathrm{~kg}), T 0=298(\mathrm{~K})
\end{aligned}
$$

Pareto optimal frontier for two objective functions, objective function associated to the first law efficiency of the system $(\eta)$ and the dimensionless output work $(w)$ of the nano scale irreversible dual cycle are represented in Figure 5a. The chosen points achieved by decision makers are marked in Figure 5. The fitted curve equation of the Pareto optimal frontier is obtained and illustrated in Figure 5b, which can be performed to achieve thermal efficiency of the system, as below:

$$
\eta=p_{1} w^{4}+p_{2} w^{3}+p_{3} w^{2}+p_{4} w+p_{5}
$$

Coefficients:

$$
\begin{aligned}
& p_{1}=-2.0288 \times 10^{6} \\
& p_{2}=7.8007 \times 10^{6} \\
& p_{3}=-1.1247 \times 10^{7} \\
& p_{4}=7.2074 \times 10^{6} \\
& p_{5}=-1.732 \times 10^{6}
\end{aligned}
$$

Figures 6-8 depict the changing of different values of decision variables in their established range for the optimum design points on the front of Pareto. The changing of the $y$ variable is demonstrated through Figure 6 .

In Figure 7 the blue line, shows the greatest magnitude of $z$ which is equal to 1.5 . Figure 8 depicts the scatter of $x$ for the optimal points on Pareto front, although the lower and upper values of the aforementioned parameters are highlighted.

Table 1 summarizes the optimum answers achieved for decision variables and objective functions employing Fuzzy, TOPSIS and LINMAP methods for first scenario.

To calculate the deviation of the answers achieved from each decision maker, error analysis was employed. Table 2 reports MAAE (Maximum Absolute Percentage Error) and MAPE (Mean Absolute Percentage Error) of three decision makers executed in this study.
Table 1. Decision making of multi-objective optimal solutions for first scenario.

\begin{tabular}{cccccc}
\hline \multirow{2}{*}{ Decision Making Method Decision variables } & \multicolumn{2}{c}{ Objectives } \\
\cline { 2 - 6 } & $y$ & $z$ & $x$ & $w$ & $\eta$ \\
\hline TOPSIS & 1.900 & 1.500 & 7.660 & 0.960 & 0.700 \\
LINMAP & 1.900 & 1.500 & 7.503 & 0.962 & 0.697 \\
Fuzzy & 1.900 & 1.500 & 7.374 & 0.963 & 0.694 \\
\hline
\end{tabular}

Table 2. Error analysis based on the mean absolute percent error (MAPE) method for first scenario.

\begin{tabular}{ccccccc}
\hline $\begin{array}{c}\text { Decision Making } \\
\text { Method }\end{array}$ & TOPSIS & LINMAP & \multicolumn{2}{c}{ Fuzzy } \\
\hline Objectives & $w$ & $\eta$ & $w$ & $\eta$ & $w$ & $\eta$ \\
\hline Max Error $\%$ & 0.046 & 0.125 & 0.024 & 0.074 & 0.573 & 1.464 \\
Average Error $\%$ & 0.019 & 0.057 & 0.018 & 0.060 & 0.271 & 0.776 \\
\hline
\end{tabular}

\subsection{Results of second scenario}

Two strategic objective functions for optimization comprise dimensionless output work and the dimensionless ecological function (should be maximized) formulated via Equations (20) and (21), correspondingly.

Objective functions are illustrated by Equations (20) and (21) limitations are formulated with Equations (24) and (21) employed to perform optimization.

Properties of the nano scale irreversible dual cycle are proposed as below [110]

$$
\begin{aligned}
R & =10^{-8}(\mathrm{~m}), H=3 \times 10^{-8}(\mathrm{~m}), \\
T_{4} & =700(\mathrm{~K}), T_{1}=100(\mathrm{~K}), \\
k & =1.0381 \times 10^{-23}(\mathrm{~J}), \\
h & =6.6262 \times 10^{-34}(\mathrm{~J} . \mathrm{s}), \\
m & =6.6474 \times 10^{-27}(\mathrm{~kg}), T_{0}=298(\mathrm{~K})
\end{aligned}
$$

Figure 9a demonstrates the Pareto frontier achieved in the second optimization scenario. Three final answers were chosen by the Fuzzy Bellman-Zadeh, LINMAP and TOPSIS decision-makers which are highlighted in this figure. According to Figure 9a, the obtained points by LINMAP and TOPSIS are approached towards each other. Also, it was shown that the optimal value of the dimensionless output work varied from 0.955 to 0.970 and the optimal value of dimensionless ecological function was between 0.117 and 0.353 . Based on the obtained curve fit depicted in Figure 9b, Equation (30) was developed.

$$
e c f=p_{1} w^{4}+p_{2} w^{3}+p_{3} w^{2}+p_{4} w+p_{5}
$$

Coefficients:

$$
\begin{aligned}
& p_{1}=-1.9455 \times 10^{7} \\
& p_{2}=7.4843 \times 10^{7} \\
& p_{3}=-1.0797 \times 10^{8} \\
& p_{4}=6.9227 \times 10^{7} \\
& p_{5}=-1.6645 \times 10^{7}
\end{aligned}
$$


M.H. Ahmadi et al.: Mechanics \& Industry 18, 212 (2017)

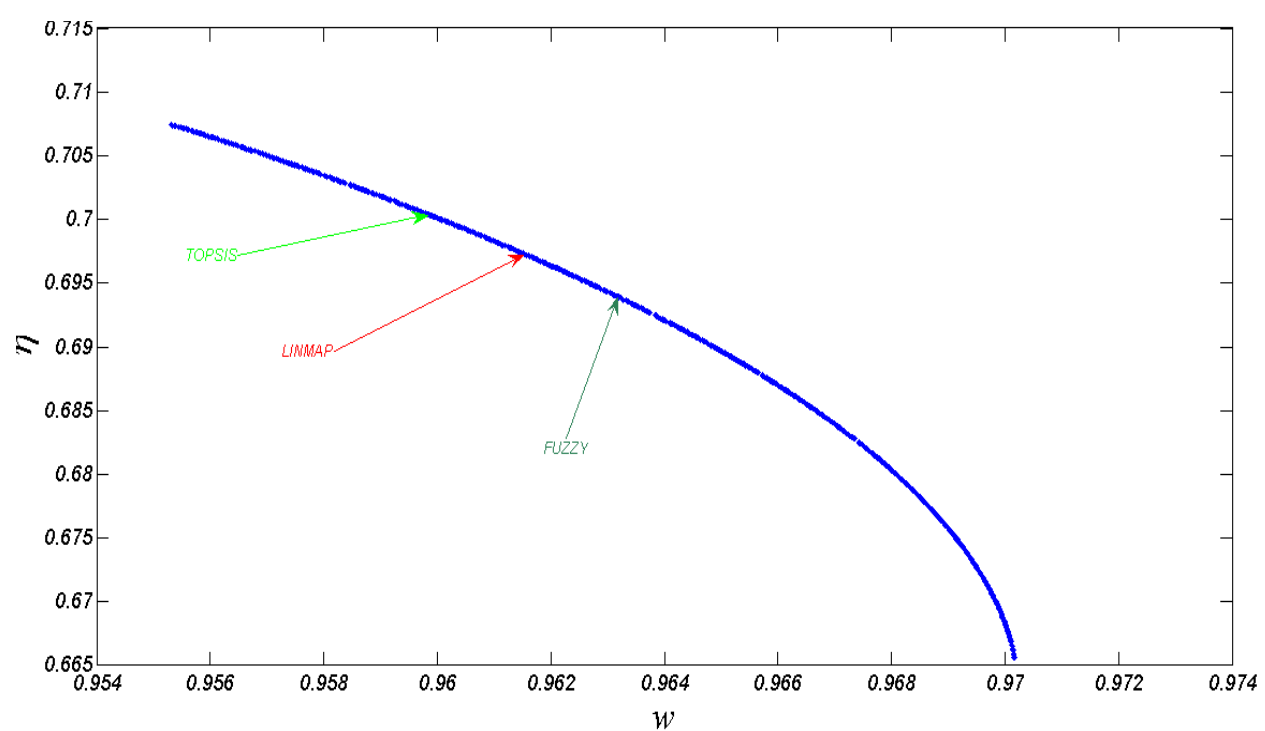

(a)

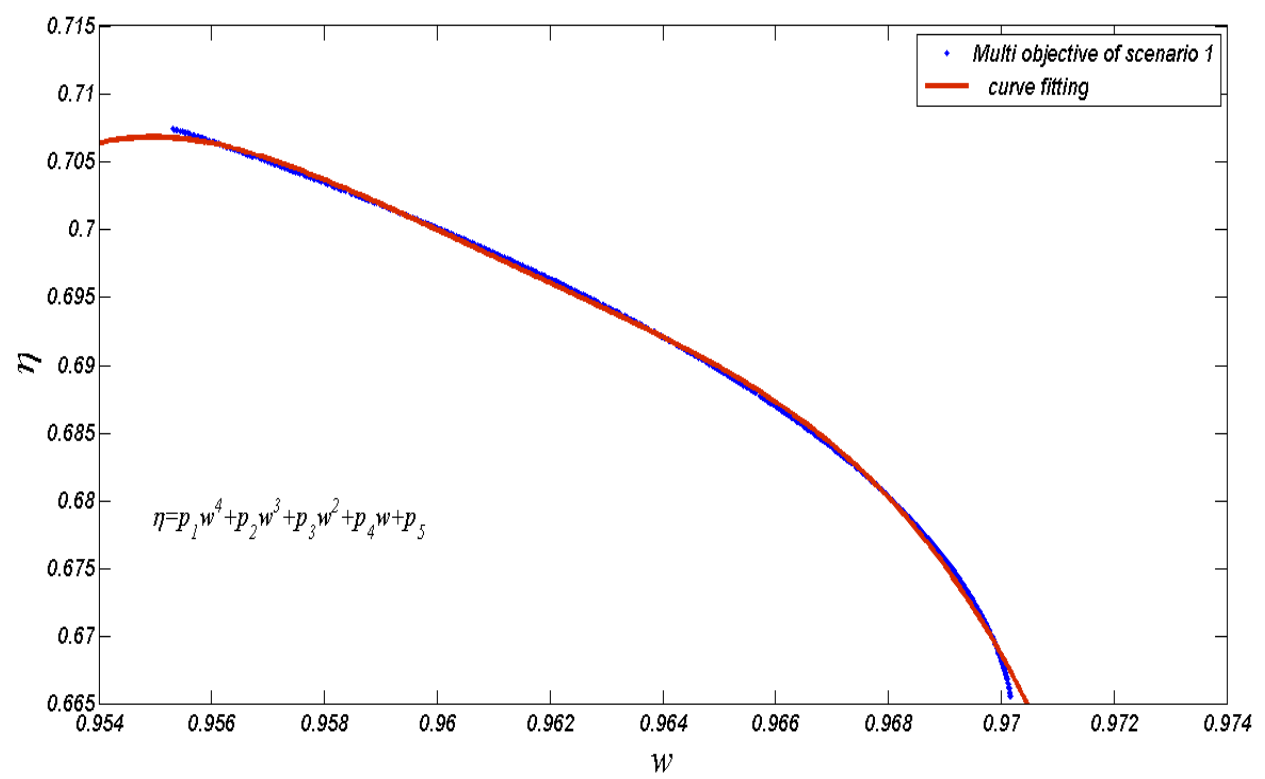

(b)

Fig. 5. (a) and (b) Pareto optimal frontier in the objectives' space for first scenario.

Figures 10-12 depict the changing of different values of decision variables in their established range for the optimum design points on the front of Pareto. The changing of the $y$ variable is demonstrated through Figure 10 .

In Figure 11 the blue line, shows the greatest magnitude of $z$ which is equal to 1.5 . Figure 12 depicts the scatter of $x$ for the optimal points on Pareto front, although the lower and upper values of the aforementioned parameters are highlighted.

Table 3 summarizes the optimum answers achieved for decision variables and objective functions employing Fuzzy, TOPSIS and LINMAP methods for second scenario.
Table 3. Decision making of multi-objective optimal solutions for second scenario.

\begin{tabular}{cccccc}
\hline \multirow{2}{*}{\begin{tabular}{c} 
Decision Making \\
\cline { 2 - 6 } Method
\end{tabular}} & $y$ & $z$ & $x$ & $w$ & $e c f$ \\
TOPSIS & 1.900 & 1.500 & 7.995 & 0.955 & 0.353 \\
LINMAP & 1.900 & 1.500 & 7.992 & 0.955 & 0.352 \\
Fuzzy & 1.900 & 1.500 & 7.597 & 0.960 & 0.313 \\
\hline
\end{tabular}

To calculate the deviation of the answers achieved from each decision maker, error analysis was employed. 
M.H. Ahmadi et al.: Mechanics \& Industry 18, 212 (2017)

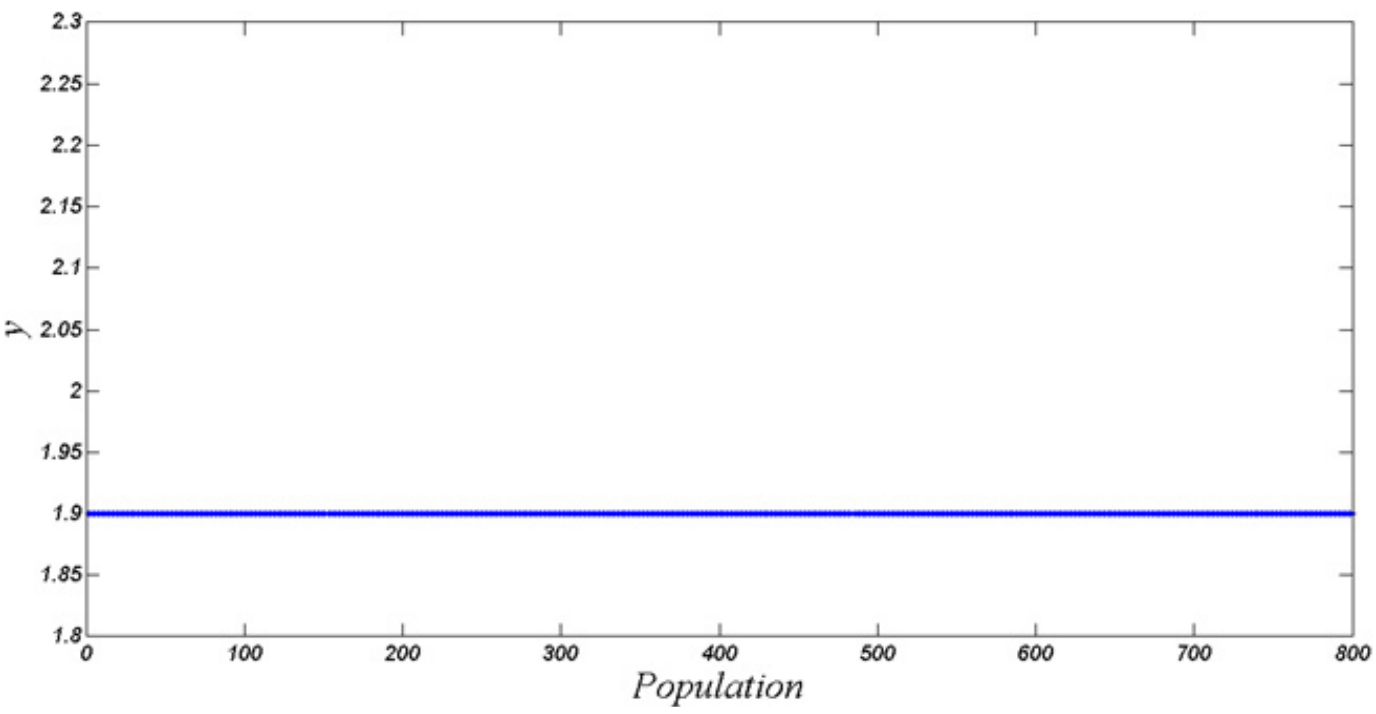

Fig. 6. The distribution of $y$ for the optimal points on Pareto front for first scenario.

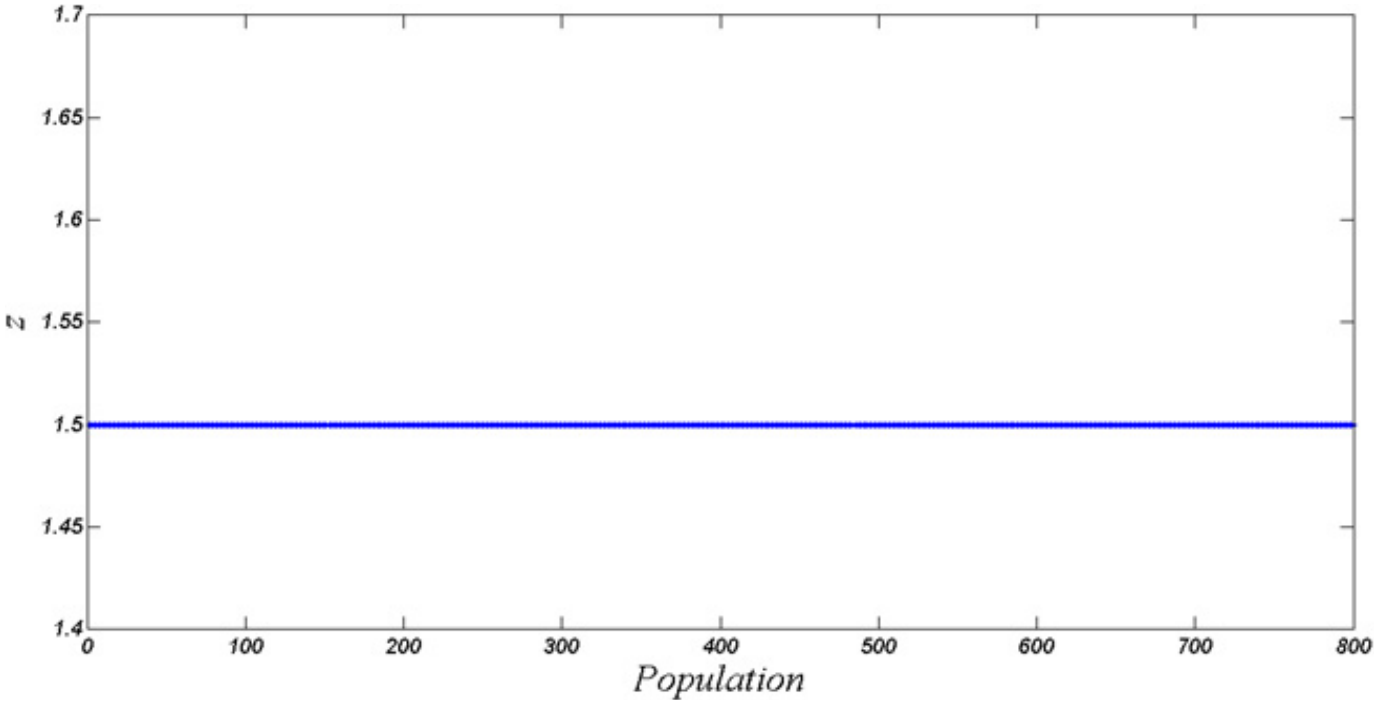

Fig. 7. The distribution of $z$ for the optimal points on Pareto front for first scenario.

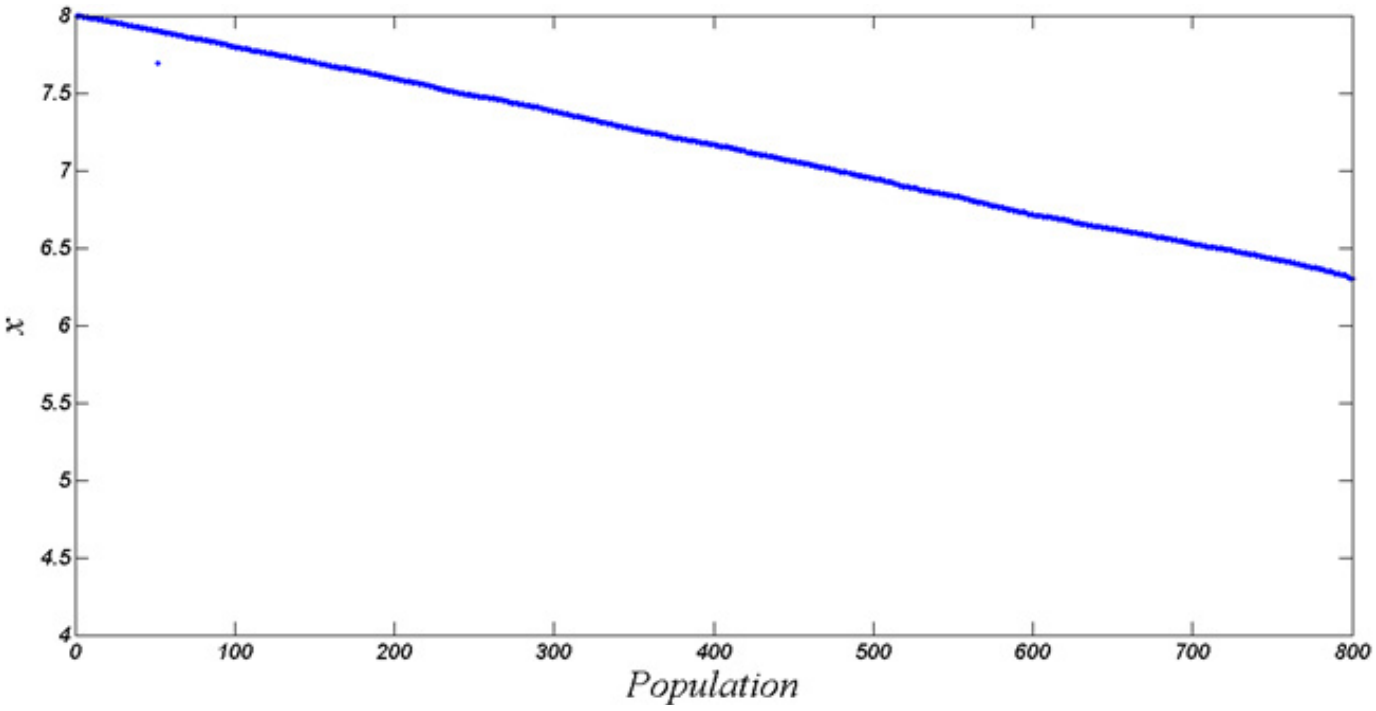

Fig. 8. The distribution of $x$ for the optimal points on Pareto front for first scenario. 
M.H. Ahmadi et al.: Mechanics \& Industry 18, 212 (2017)

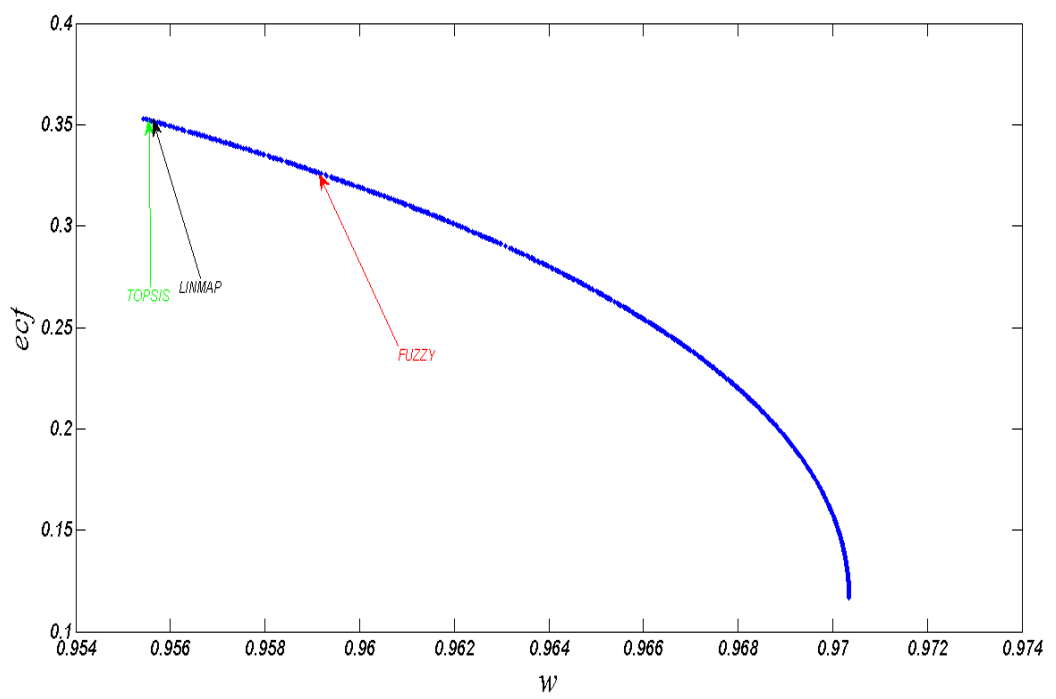

(a)

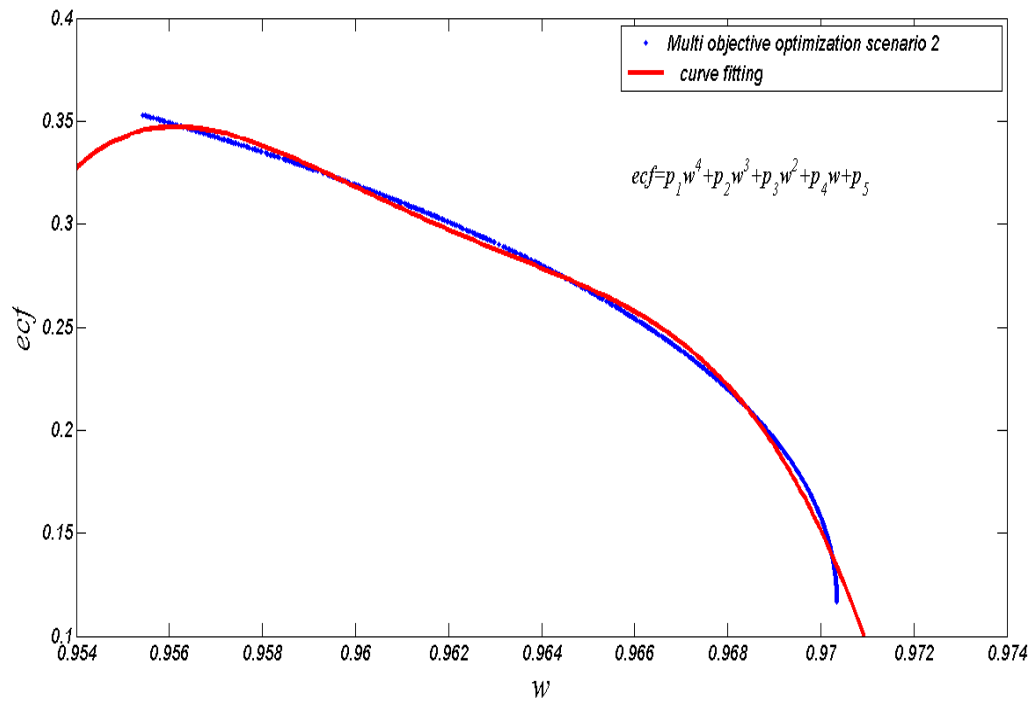

(b)

Fig. 9. (a) and (b) Pareto optimal frontier in the objectives' space for second scenario.

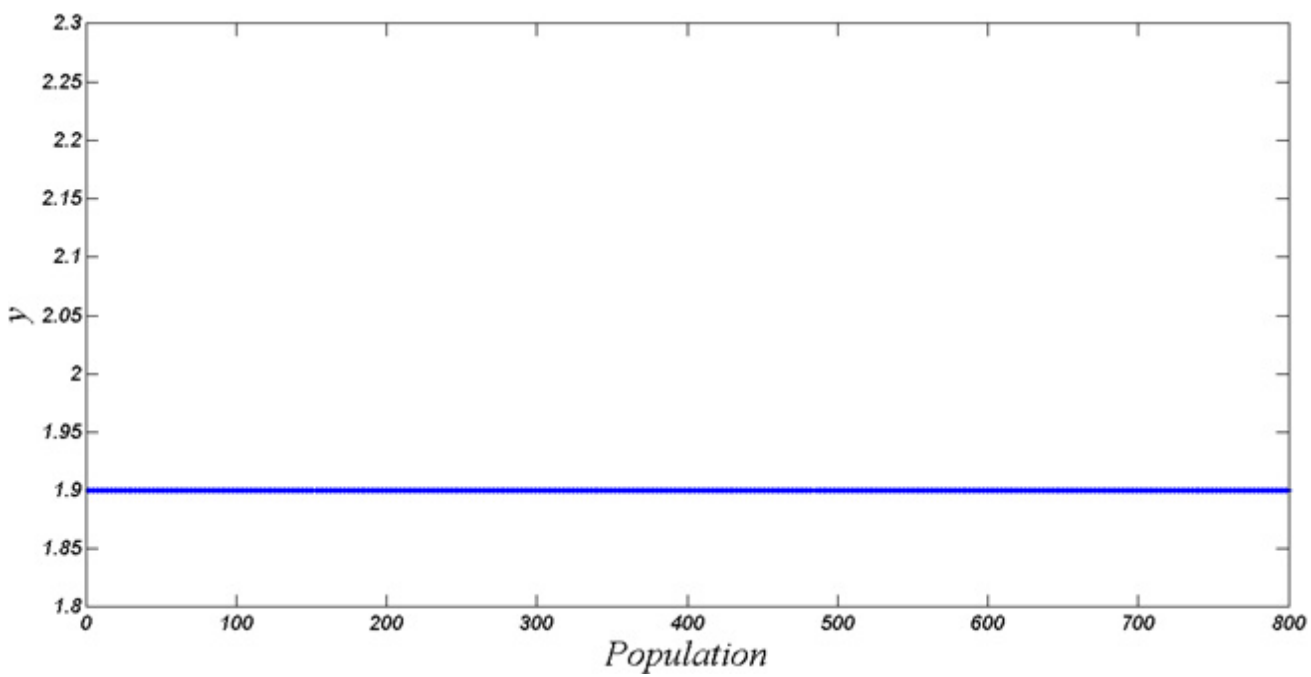

Fig. 10. The distribution of $y$ for the optimal points on Pareto front for second scenario. 
M.H. Ahmadi et al.: Mechanics \& Industry 18, 212 (2017)

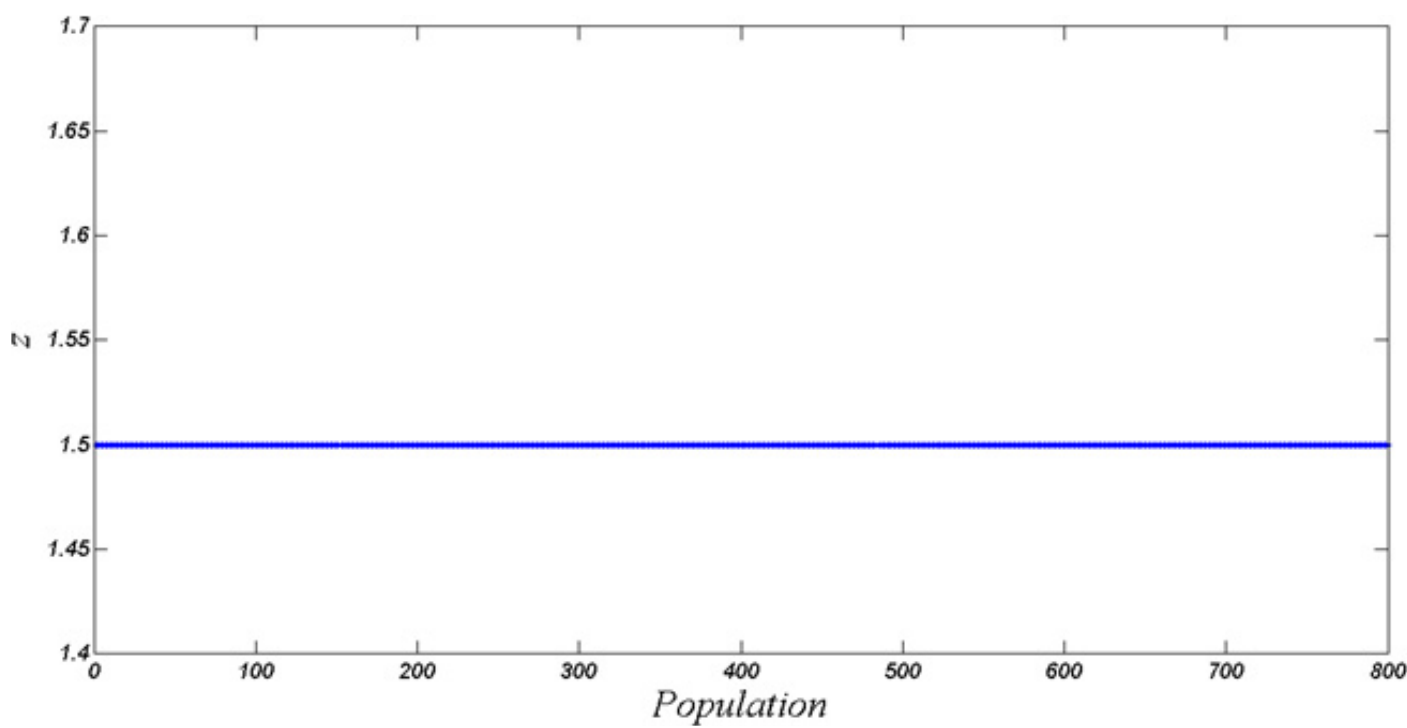

Fig. 11. The distribution of $z$ for the optimal points on Pareto front for second scenario.

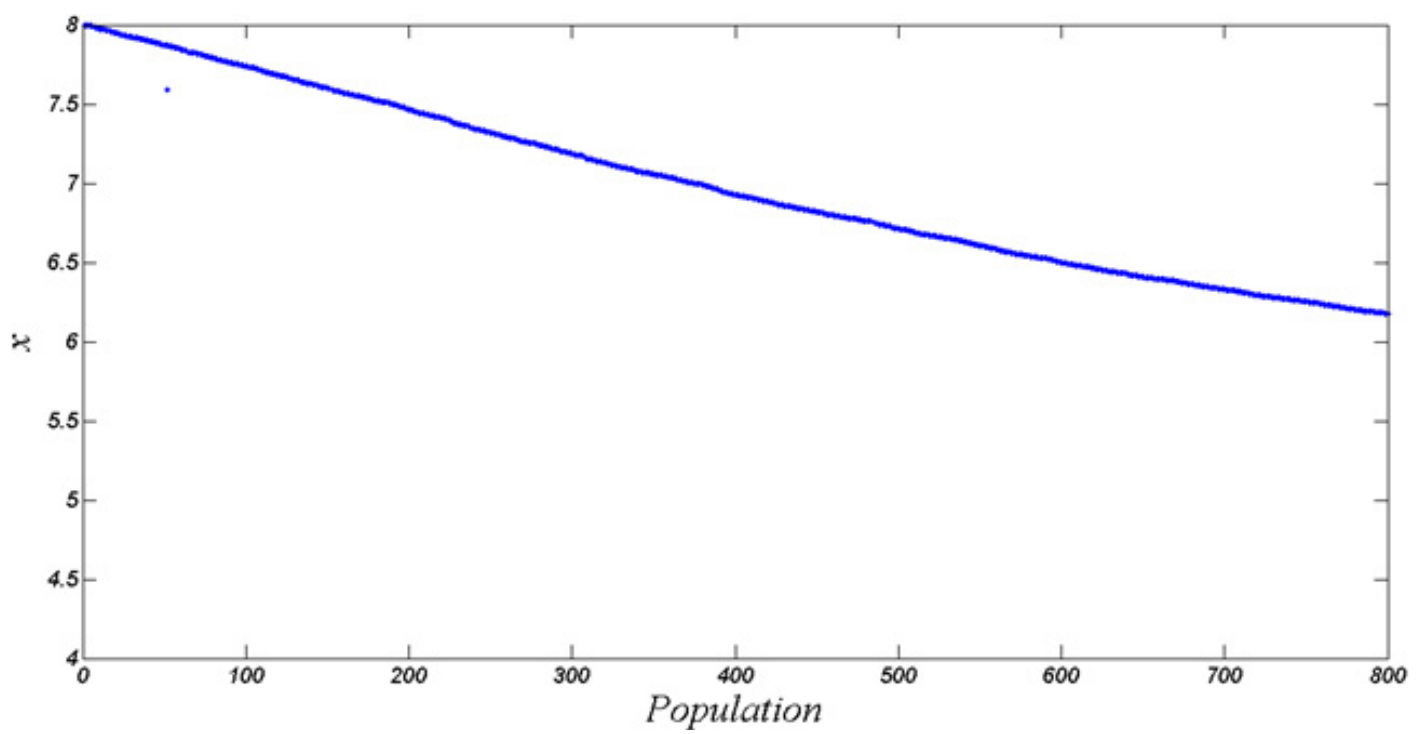

Fig. 12. The distribution of $x$ for the optimal points on Pareto front for second scenario.

Table 4. Error analysis based on the mean absolute percent error (MAPE) method for second scenario.

\begin{tabular}{ccccccc}
\hline $\begin{array}{c}\text { Decision } \\
\text { Making } \\
\text { Method }\end{array}$ & TOPSIS & LINMAP & Fuzzy \\
\hline Objectives & $w$ & $e c f$ & $w$ & $e c f$ & $w$ & $e c f$ \\
\hline Max Error \% & 0.008 & 0.261 & 0.010 & 0.261 & 0.247 & 6.246 \\
Average Error \% & 0.006 & 0.142 & 0.008 & 0.184 & 0.143 & 3.726 \\
\hline
\end{tabular}

Table 4 reports MAAE and MAPE of three decision makers executed in this study.

\section{Conclusions}

In this paper the thermodynamic analysis is applied on the nano scale irreversible dual cycle. Further effects of the compression ratio, the pressure ratio and the cutoff ratio are included in evaluation of the dimensionless output work, the dimensionless ecological function and the first law efficiency of the nano scale irreversible dual cycle executing thermodynamic analysis. Moreover, the optimum settings of the aforementioned objective functions comprising the dimensionless output work, the dimensionless ecological function and the first law efficiency for the nano scale irreversible dual cycle are specified. 
In the evolved multi-objective optimization approach, three separate variables, the compression ratio, the pressure ratio and the cut-off ratio, are presumed as the decision variables. To indicate a final solution from the outcomes obtained via multi-objective optimization progress, three well-known decision making approaches are employed and final results are compared based on the error analysis.

\section{References}

[1] F.L. Curzon, B. Ahlborn, Efficiency of a Carnot engine at maximum power-output, Am. J. Phys. 43 (1975) 2224

[2] I.I. Novikov, The efficiency of atomic power stations, J. Nucl. Energy 11 (1958) 25-28

[3] F. Angulo-Brown, An ecological optimization criterion for finite-time heat engines, J. Appl. Phys. 69 (1991) $7465-7469$

[4] Z. Yan, Comment on ecological optimization criterion for finite-time heat-engines, J. Appl. Phys. 73 (1993) 3583

[5] L. Chen, W. Zhang, F. Sun, Power, efficiency, entropygeneration rate, ecological optimization for a class of generalized irreversible universal heat engine cycles, Appl. Energy 84 (2007) 512-525

[6] L. Chen, J. Zhou, F. Sun, C. Wu, ecological optimization for generalized irreversible Carnot engines, Appl. Energy 77 (2004) 327-338

[7] Y. Huang, D. Sun, Y. Kang, Performance optimization for an irreversible four temperature-level absorption heat pump, Int. J. Therm. Sci. 4 (2008) 7479-7485

[8] Z. Yan, G. Lin, Ecological optimization criterion for an irreversible three-heat-source refrigerator, Appl. Energy 66 (2000) 213-224

[9] C. Cheng, C. Chen, The ecological optimization of an irreversible Carnot heat-engine, J. Phys. D 30 (1997) 1602-1609

[10] D. Xia, L. Chen, F. Sun, Universal ecological performance for endoreversible heat engine cycles, Int. J. Ambient Energy 27 (2001) 15-20.

[11] W. Zhang, L. Chen, F. Sun, C. Wu, Exergy-based ecological optimal performance for a universal endoreversible thermodynamic cycle, Int. J. Ambient Energy 28 (2007) 51-56

[12] L. Chen, X. Zhu, F. Sun, C. Wu, Exergy-based ecological optimization of linear phenomenological heat transfer law irreversible Carnot engines, Appl. Energy 83 (2006) $573-582$

[13] X. Zhu, L. Chen, F. Sun, C. Wu, The ecological optimization of a generalized irreversible Carnot engine with a generalized heat-transfer law, Int. J. Ambient Energy 24 (2003) 189-194

[14] X. Zhu, L. Chen, F. Sun, C. Wu, Effect of heat transfer law on the ecological optimization of a generalized irreversible Carnot engine, Open Syst. Inf. Dyn. 12 (2005) 249-260

[15] J. Li, L. Chen, F. Sun, Ecological performance of an endoreversible Carnot heat engine with complex heat transfer law, Int. J. Sustain. Energy 30 (2011) 55-64
[16] J. Li, L. Chen, F. Sun, Ecological performance of a generalized irreversible Carnot heat engine with complex heat transfer law, Int. J. Energy Environ. 2 (2011) 5770

[17] Y. Tu, L. Chen, F. Sun, C. Wu, Exergy-based ecological optimization for an endoreversible Brayton refrigeration cycle, Int. J. Exergy 3 (2006) 191-201

[18] L. Chen, X. Zhu, F. Sun, C. Wu, Ecological optimization for generalized irreversible Carnot refrigerators, J. Phys. D 38 (2005) 113-118

[19] L. Chen, X. Zhu, F. Sun, C. Wu, Exergy-based ecological optimization for a generalized irreversible Carnot heatpump, Appl. Energy 84 (2007) 78-88

[20] X. Zhu, L. Chen, F. Sun, C. Wu, Exergy based ecological optimization for a generalized irreversible Carnot refrigerator, J. Energy Inst. 79 (2006) 42-46

[21] L. Chen, X. Zhu, F. Sun, C. Wu, Ecological optimization of a generalized irreversible Carnot refrigerator for a generalized heat transfer law, Int. J. Ambient Energy 28 (2007) 213-219

[22] J. Li, L. Chen, F. Sun, C. Wu, Ecological performance of an endoreversible Carnot refrigerator with complex heat transfer law, Int. J. Ambient Energy 32 (2011) 31-36.

[23] L. Chen, J. Li, F. Sun, Ecological optimization of a generalized irreversible Carnot refrigerator in case of $\mathrm{Q} \infty(\Delta \mathrm{T} \mathrm{n}) \mathrm{m}$, Int. J. Sustain. Energy 31 (2012) 59-72

[24] S.K. Tyagi, S.C. Kaushik, R. Salohtra, Ecological optimization, parametric study of irreversible Stirling, Ericsson heat pumps, J. Phys. D 35 (2002) 2058-2065

[25] X. Zhu, L. Chen, F. Sun, C. Wu, Effect of heat transfer law on the ecological optimization of a generalized irreversible Carnot heat pump, Int. J. Exergy 2 (2005) 423-436

[26] X. Zhu, L. Chen, F. Sun, C. Wu, The ecological optimization of a generalized irreversible Carnot heat pump for a generalized heat transfer law, J. Energy Inst. 78 (2005) 5-10

[27] L. Chen, J. Li, F. Sun, C. Wu, Effect of a complex generalized heat transfer law on ecological performance of an endoreversible Carnot heat pump, Int. J. Ambient Energy 30 (2009) 102-108

[28] J. Li, L. Chen, F. Sun, Optimal ecological performance of a generalized irreversible Carnot heat pump with a generalized heat transfer law, Termotehnica Therm. Eng. 13 (2009) 61-68

[29] X. Liu, L. Chen, F. Wu, F. Sun, Ecological optimization of an irreversible harmonic oscillator Carnot heat engine, Sci. China Ser. G: Phys. Mech. Astron. 52 (2009) 1976-1988

[30] W. Wang, L. Chen, F. Sun, C. Wu, Optimal heat conductance distribution, optimal intercooling pressure ratio for power optimization of an irreversible closed intercooled regenerated Brayton cycle, J. Energy Inst. 79 (2006) 116-119

[31] W. Wang, L. Chen, F. Sun, Ecological optimization of an irreversible ICR gas turbine cycle, Int. J. Exergy 9 (2011) 66-79

[32] S.K. Tyagi, S.C. Kaushik, R. Salhotra, Ecological optimization, performance study of irreversible Stirling, Ericsson heat engines, J. Phys. D 35 (2002) 2668-2675

[33] X. Zhu, L. Chen, F. Sun, C. Wu, Exergy-based ecological optimization for a generalized Carnot refrigerator, J. Energy Inst. 79 (2006) 42-46 
[34] C. Wu, L. Chen, F. Sun, Ecological optimization performance of an irreversible quantum SI engine powering with an ideal Fermi gas, Open Syst. Inf. Dyn. 13 (2006) $55-66$.

[35] E. Acıkkalp, Models for optimum thermo-ecological criteria of actual thermal cycles, Therm. Sci. 17 (2013) 915-930

[36] E. Acıkkalp, Modified thermo-ecological optimization for refrigeration systems and an application for irreversible four-temperature-level absorption refrigerator, Int. J. Energy Environ. Eng. 4 (2013) 20.

[37] Y. Ust, B. Sahin, O.S. Sogut, Performance analysis, optimization of an irreversible dual-cycle based on an ecological coefficient of performance criterion, Appl. Energy 82 (2005) 23-39

[38] Y. Ust, B. Sahim, Performance optimization of irreversible refrigerators based on a new thermo-ecological criterion, Int. J. Refrig. 30 (2007) 527-534

[39] Y. Ust, B. Sahin, A. Kodal, I.H. Akcay, Ecological coefficient of performance analysis, optimization of an irreversible regenerative-Brayton heat engine, Appl. Energy 83 (2006) 558-572

[40] S.S. Sogut, Y. Ust, B. Sahin, The effects of intercooling, regeneration on thermo-ecological performance analysis of an irreversible-closed Brayton heat engine with variable-temperature thermal reservoirs, J. Phys. D 39 (2006) 4713-4721

[41] Y. Ust, Effect of regeneration on the thermo-ecological performance analysis, optimization of irreversible air refrigerators, Heat Mass Transfer 46 (2010) 469-478

[42] Y. Ust, Performance analysis, optimization of irreversible air refrigeration cycles based on ecological coefficient of performance criterion, Appl. Therm. Eng. 29 (2009) 47-55.

[43] Y. Ust, O.S. Sogut, B. Sahin, A. Durmayaz, Ecological coefficient of performance ECOP optimization for an irreversible Brayton heat engine with variable temperature thermal reservoirs, J. Energy Inst. 79 (2006) 47-52

[44] Y. Ust, B. Sahin, A. Kodal, Performance analysis of an irreversible Brayton heat engine based on ecological coefficient of performance criterion, Int. J. Therm. Sci. 45 (2006) 94-101.

[45] Y. Ust, B. Sahin, A. Kodal, Ecological coefficient of performance ECOP optimization for generalized irreversible Carnot heat engines, J. Energy Inst. 78 (2005) $145-151$.

[46] Y. Ust, B. Sahin, A. Safa, Ecological performance analysis of an endoreversible regenerative Brayton heatengine, Appl. Energy 80 (2005) 247-260

[47] Y. Ust, A.V. Akkaya, A. Safa, Analysis of a vapour compression refrigeration system via exergetic performance coefficient criterion, J. Energy Inst. 84 (2011) 66-72

[48] A.V. Akkaya, B. Sahin, H.H. Erdem, An analysis of SOFC/GT CHP system based on exergetic performance criteria, Int. J. Hydrog. Energy 10 (2008) 2566-2577

[49] A.V. Akkaya, B. Sahin, H.H. Erdem, Exergetic performance coefficient analysis of a simple fuel cell system, Int. J. Hydrog. Energy 17 (2007) 4600-4609

[50] Y. Ust, B. Sahin, A. Kodal, Optimization of a dual cycle cogeneration system based on a new exergetic performance criterion, Appl. Energy 84 (2007) 1079-1091

[51] Y. Ust, B. Sahin, T. Yilmaz, Optimization of a regenerative gas-turbine cogeneration system based on a new exergetic performance criterion: exergetic performance coefficient EPC, Proc. Inst. Mech. Eng. A 221 (2007) $447-456$

[52] E. Acıkkalp, H. Yamı, Limits and optimization of power input or output of actual thermal cycles, Entropy 15 (2013) 3219-3248

[53] F. Wu, L. Chen, F. Sun, C. Wu, F. Guo, Q. Li, Quantum degeneracy effect on performance of irreversible Otto cycle with ideal Bose gas, Energy Convers. Manage. 47 (2006) 3008-3018

[54] J. He, H. Wang, S. Liu, Performance characteristics of a quantum Diesel refrigeration cycle, Energy Convers. Manage. 50 (2009) 933-937

[55] H. Saygın, A. ŞiŞman, Brayton refrigeration cycles working under quantum degeneracy conditions, Appl. Energy 69 (2001) 77-85

[56] J. He, J. Chen, B. Hua, Influence of quantum degeneracy on the performance of a Stirling refrigerator working with an ideal Fermi gas, Appl. Energy 72 (2002) 541554

[57] Y. Yang, B. Lin, J. Chen, Influence of regeneration on the performance of a Brayton refrigeration-cycle working with an ideal Bose-gas, Appl. Energy 83 (2006) 99112

[58] B. Lin, Y. Zhang, J. Chen, Influence of quantum degeneracy and regeneration on the performance of BoseStirling refrigeration-cycles operated in different temperature regions, Appl. Energy 83 (2006) 513-535

[59] W. Nie, Q. Liao, C.Q. Zhang, J. He, Micro-/nanoscaled irreversible Otto engine cycle with friction loss and boundary effects and its performance characteristics, Energy 35 (2010) 4658-4662

[60] J. Guo, X. Zhang, G. Su, J. Chen, The performance analysis of a micro-/nanoscaled quantum heat engine, Phys. A 391 (2012) 6432-6439

[61] H. Wang, S. Liu, J. He, Optimum criteria of an irreversible quantum Brayton refrigeration cycle with an ideal Bose gas, Physica B 403 (2008) 3867-3878

[62] J. Liu, B. Lin, W. Hu, J. Chen, Influence of multiirreversibilities on the performance of a Brayton refrigeration cycle working with an ideal Bose or Fermi gas, Int. J. Therm. Sci. 47 (2008) 1374-1381

[63] H. Wang, S. Liu, J. He, Performance analysis and parametric optimum criteria of a quantum Otto heat engine with heat transfer effects, Appl. Therm. Eng. 29 (2009) $706-711$

[64] A. SiSman, H. Saygin, On the power cycles working with ideal quantum gases: I. The Ericsson cycle, J. Phys. D 32 (1999) 664-670.

[65] J. Chen, J. He, B. Hua, The influence of regenerative losses on the performance of a Fermi Ericsson refrigeration cycle, J. Phys. A 35 (2002) 7995-8004

[66] Y. Zhang, B. Lin, J. Chen, The influence of quantum degeneracy and irreversibility on the performance of a Fermi quantum refrigeration cycle, J. Phys. A 37 (2004) $7485-7497$

[67] A. ŞiŞman, H. Saygin, Efficiency analysis of a Stirling power cycle under quantum degeneracy conditions, Phys. Scr. 63 (2001) 263-267

[68] A. SiiŞman, H. Saygin, Re-optimization of Otto power cycles working with ideal quantum gasses, Phys. Scr. 64 (2001) 108-112 
[69] H. Wang, S. Liu, J. Du, Performance analysis and parametric optimum criteria of a regeneration Bose-Otto engine, Phys. Scr. 79 (2009) 055004

[70] W. Hao, W. Guo-Xing, Optimization criteria of a Bose Brayton heat engine, Chin. Phys. B 21 (2012) 010505

[71] A. ŞiŞman, H. Saygin, The improvement effect of quantum degeneracy on the work from a Carnot cycle, Appl. Energy 68 (2001) 367-376

[72] H. Saygın, ŞiŞman, Brayton refrigeration cycles working under quantum degeneracy conditions, Appl. Energy 69 (2001) 77-85

[73] B. Lin, J. Chen, The performance analysis of a quantum Brayton refrigeration cycle with ideal Bose gas, Open Syst. Inf. Dyn. 10 (2003) 147-157

[74] B. Lin, J. Chen, The influence of quantum degeneracy on the performance of a Fermi Brayton engine, Open Syst. Inf. Dyn. 11 (2004) 87-99

[75] F. Wu, L. Chen, F. Sun, C. Wu, F. Guo, Optimal performance of an irreversible quantum Brayton refrigerator with ideal Bose gases, Phys. Scr. 73 (2006) 452-457

[76] U. Lucia, Quanta and entropy generation, Physica A 419 (2015) 115-121.

[77] U. Lucia, Maximum or minimum entropy generation for open systems? Physica A 391 (2012) 3392-3398

[78] U. Lucia, Maximum entropy generation and k-exponential model, Physica A 389 (2010) 45584563

[79] U. Lucia, Irreversibility, entropy and incomplete information, Physica A 388 (2009) 4025-4033

[80] J. Lin, L. Chen, C. Wu, et al., Finite-time thermodynamic performance of Dual cycle, Int. J. Energy Res. 23 (1999) 765-772

[81] W. Wang, L. Chen, F. Sun, et al., The effects of friction on the performance of an air stand Dual cycle, Exergy Int. J. 2 (2002) 340-344

[82] L. Chen, Y. Ge, F. Sun, et al., Effects of heat transfer, friction and variable specific heats of working fluid on performance of an irreversible Dual cycle, Energy Convers. Manage. 47 (2006) 3224-3234

[83] Y. Ge, L. Chen, F. Sun, Finite time thermodynamic modeling and analysis for an irreversible Dual cycle, Math. Comput. Modell. 50 (2009) 101-108

[84] T. Özyer, M. Zhang, R. Alhajj, Integrating multiobjective genetic algorithm based clustering and data partitioning for skyline computation, Appl. Intell. 35 (2011) 110-122

[85] O. Beatrice, J.R. Brian, H. Franklin, Multi-Objective Genetic Algorithms for Vehicle Routing Problem with Time Windows, Appl. Intell. 24 (2006) 17-30

[86] I. Blecic, A. Cecchini, G. Trunfio, A decision support tool coupling a causal model and a multi-objective genetic algorithm, Appl. Intell. 26 (2007) 125-137

[87] D.A.V. Veldhuizen, G.B. Lamont, Multi objective evolutionary algorithms analyzing the state-of-the-art, Evol. Comput. 8 (2000) 125-47

[88] A. Konak, D.W. Coit, A.E. Smith, Multi-objective optimization using genetic algorithms: A tutorial, Reliab. Eng. Syst. Safety 91 (2006) 992-1007

[89] M.H. Ahmadi, H. Hosseinzade, H. Sayyaadi, A.H. Mohammadi, F. Kimiaghalam, Application of the multiobjective optimization method for designing a powered Stirling heat engine: design with maximized power, thermal efficiency and minimized pressure loss, Renew. Energy 2013 (60) 313-22
[90] M.H. Ahmadi, H. Sayyaadi, A.H. Mohammadi, A. Marco, Barranco-Jimenez. Thermo-economic multiobjective optimization of solar dish-Stirling engine by implementing evolutionary algorithm, Energy Convers. Manage. 73 (2013) 370-380

[91] Ahmadi MH, Sayyaadi H, Dehghani S, Hosseinzade H. Designing a solar powered Stirling heat engine based on multiple criteria: Maximized thermal efficiency and power, Energy Convers. Manage. 75 (2013) 282-291

[92] M.H. Ahmadi, S. Dehghani, A.H. Mohammadi, M. Feidt, A. Marco, Barranco-Jimenez. Optimal design of a solar driven heat engine based on thermal and thermoeconomic criteria, Energy Convers. Manag. 75 (2013) 635-642

[93] Ahmadi Pouria, Dincer Ibrahim, Rosen Marc A. Thermodynamic, modeling and multi-objective evolutionary-based optimization of a new multigeneration energy system. Energy Convers. Manage. 76 (2013) 282-300

[94] A. Lazzaretto, A. Toffolo, Energy, economy and environment as objectives in multi-criterion optimization of thermal systems design, Energy 29 (2004) 1139-1157

[95] S. Toghyani, A. Kasaeian, M.H. Ahmadi, Multiobjective optimization of Stirling engine using non-ideal adiabatic method, Energy Convers. Manag. 80 (2014) $54-62$

[96] A. Toffolo, A. Lazzaretto, Evolutionary algorithms for multi-objective energetic and economic optimization in thermal system design, Energy 27 (2002) 549-567

[97] M.H. Ahmadi, A.H. Mohammadi, S. Dehghani, Evaluation of the maximized power of a regenerative endoreversible Stirling cycle using the thermodynamic analysis, Energy Convers. Manage. 76 (2013) 561-570

[98] Mo.H. Ahmadi, M. Ali Ahmadi, A. H. Mohammadi, M. Feidt, S. Mohsen Pourkiaei, Multi-objective optimization of an irreversible Stirling cryogenic refrigerator cycle, Energy Convers. Manage. 82 (2014) 351-360

[99] M.H. Ahmadi, M.A. Ahmadi, A.H. Mohammadi, M. Mehrpooya, M. Feidt, Thermodynamic optimization of Stirling heat pump based on multiple criteria, Energy Convers. Manage. 80 (2014) 319-328

[100] M.H. Ahmadi, A.H. Mohammadi, S. Dehghani, A. Marco, Barranco-Jimenez Multi-objective thermodynamic-based optimization of output power of Solar Dish-Stirling engine by implementing an evolutionary algorithm, Energy Convers. Manag. 75 (2013) 438-445

[101] M.H. Ahmadi, A.H. Mohammadi, S.M. Pourkiaei, Optimisation of the thermodynamic performance of the Stirling engine. Int. J. Ambient Energy, DOI: 10.1080/01430750.2014.907211

[102] H. Sayyaadi, M. Hossein Ahmadi, S. Dehghani, Optimal Design of a Solar-Driven Heat Engine Based on Thermal and Ecological Criteria. J. Energy Eng., DOI: 10.1061/(ASCE)EY.1943-7897.0000191 (2014) 04014012

[103] R. Soltani, P. Mohammadzadeh Keleshtery, M. Vahdati, M.H. Khoshgoftar Manesh, M.A. Rosen, M. Amidpour, Multi-objective optimization of a solar-hybrid cogeneration cycle: Application to CGAM problem, Energy Convers. Manage. 81 (2014) 60-71 
[104] Ahmadi MH, Ahmadi MA, Mehrpooya M, Hosseinzade H, Feidt M. Thermodynamic and thermoeconomic analysis and optimization of performance of irreversible four-temperature-level absorption refrigeration, Energy Convers. Manage. 88 (2014) 1051-9

[105] M.H. Ahmadi, M.A. Ahmadi, Thermodynamic analysis and optimization of an irreversible Ericsson cryogenic refrigerator cycle, Energy Convers. Manage. 89 (2015) $147-155$

[106] M.H. Ahmadi, M.A. Ahmadi, M. Mehrpooya, M. Sameti, Thermo-ecological analysis and optimization performance of an irreversible three-heat-source absorption heat pump, Energy Convers. Manag. 90 (2015) 175183
[107] M.H. Ahmadi, M.A. Ahmadi, M. Feidt, Performance optimization of a solar-driven multi-step irreversible brayton cycle based on a multi-objective genetic algorithm, Oil Gas Sci. Technol. - Rev. IFP Energies nouvelles. DOI: dx.doi.org/10.2516/ogst/2014028 (2014)

[108] A. ŞiŞman, Surface dependency in thermodynamics of ideal gases, J. Phys. A 37 (2004) 11353-11361

[109] A. ŞiŞman, I. Muller, The Casimir-like size effects in ideal gases, Phys. Lett. A 320 (2004) 360-366

[110] Emin Açıkkalp, Necmettin Caner, Determining performance of an irreversible nano scale dual cycle operating with Maxwell-Boltzmann gas, Physica A 424 (2015) 342-349 